\title{
Apoio ao letramento infantil por meio de construção de narrativas empregando uma ferramenta de mineração textual
}

\section{Support children's literacy through the construction of narratives using a text-mining tool}

\author{
Natércia Ricardina Langa - PPGEDU - UFRGS - naritol@gmail.com \\ Eliseo Reategui-PGIE - UFRGS - eliseoreategui@gmail.com \\ Belissar Mormelo - Universidade Estadual de Paraná-Campo Mourão - \\ belissarmormelo@gmail.com \\ Edcleia A. Basso - Universidade Estadual de Paraná-Campo Mourão- \\ edcleia@hotmail.com
}

\begin{abstract}
Resumo: $O$ artigo apresenta um estudo sobre o uso de uma tecnologia de mineração textual como elemento disparador na construção de narrativas para apoio ao letramento. As narrativas são uma das primeiras formas com a qual os jovens têm contato para ordenação de experiências, seja no relato de acontecimentos reais ou fictícios. São apresentados no trabalho os resultados de um estudo realizado com alunos de uma escola de ensino fundamental, aplicando-se uma ferramenta de mineração textual capaz de extrair conceitos relevantes de um texto e apresentá-los em forma de uma rede de conceitos ilustrados por imagens. Os resultados do estudo demonstraram que o uso da ferramenta, aliada à metodologia de produção de narrativas, auxiliou os alunos a focar sua escrita num assunto específico e relacioná-lo a suas experiências de vida.

Palavras- chaves: letramento, narrativa, mineração textual.
\end{abstract}

Abstract: This paper presents a study about the use of text mining as an element to trigger storytelling as a way to support literacy processes. Narratives are one of the first ways young people have to order their experiences, either when telling real or fictional facts. In this paper we present the results of a study carried out with students of an elementary school about storytelling supported by a text mining tool capable of extracting relevant concepts from a text, and presenting these concepts with images. Results showed that the use of the tool, together with a methodology for the writing of stories, helped students to focus in the writing of a specific topic, while relating it to their own life experiences.

Keywords: literacy, storytelling, text mining

\section{Introdução}

Para Almeida e Freitag $(2011$, p.1) as narrativas "costumam ser o primeiro tipo de texto com o qual as crianças têm contato, em todas as culturas, como ato de linguagem para ordenação da experiência, enfocando acontecimentos reais ou fictícios". Estes fatores fazem da narrativa um elemento que possibilita ao aluno desenvolver uma escrita mais fluida, pois já faz parte da história do ser humano narrar e/ou contar histórias. 
É nessa perspectiva que se insere a presente pesquisa, que busca promover o processo de escrita reflexiva e criativa através de construção de narrativas apoiadas por uma ferramenta de mineração textual que é capaz de extrair conceitos relevantes sobre um texto e apresenta-los em forma de grafo de conceitos/imagens. A mineração de texto é definida como um processo computacional pelo qual termos e/ou ideias relevantes são identificadas em dados não estruturados (texto) (Feldman e Sanger, 2006). Propõe-se aqui uma estratégia de construção de narrativas a partir de grafos extraídos automaticamente de textos, onde a partir destes grafos o aluno é desafiado a refletir sobre o conteúdo lido, e com base nisso fazer sua produção textual. Servindo a ferramenta nesse sentido como um disparador, organizador e norteador de ideias.

O artigo esta estruturado da seguinte maneira, a seção 1 que é a introdutória, na seção 2 faz-se a discussão sobre os conceitos de letramento e narrativas. Na seção 3 apresenta-se a ferramenta de mineração textual proposta e a estratégia de sua aplicação na construção de narrativas. Por fim, na seção 4 apresenta-se o estudo realizado com alunos de uma escola de ensino fundamental no sul do país.

\section{Letramento e a sua promoção através de narrativas}

O conceito de letramento está relacionado à participação ativa na leitura e escrita, envolvendo aspectos sócios históricos e culturais, estando presentes as relações dessa escrita com a oralidade, a interpretação, as condições sócias históricas e as tecnologias disponíveis no ambiente social (TFOUNI, 2010, SOARES, 2009).

A leitura tem sido vista como um ato de se colocar em relação um discurso (texto) com outros discursos anteriores a ele, emaranhados nele e posteriores a ele, como possibilidades infinitas de réplicas, gerando novos discursos/textos (Rojo, 2009, p.79). Neste sentido, a promoção do letramento requer o desenvolvimento de atividades de leitura e escrita que promovam a interpretação e a escrita livre, relacionando-as à vida social do aprendiz. E a narrativa pode tornar-se, nesse sentido, um saudável exercício de liberdade exatamente porque nela o personagem pode ser focalizado através de seu próprio discurso autoral (Machado, 1998), promovendo uma maior desenvoltura na linguagem oral ou escrita.

O termo letramento surge no vocabulário da educação e ciências linguísticas nos anos 80 , e provem do termo inglês literacy definido como a condição daquele que aprende a ler e escrever, estando implícita a idéia de que a escrita traz consequências sociais, culturais, políticas, econômicas, cognitivas, linguísticas, tanto para o indivíduo como para o grupo social em que está inserido (Soares, 2009).

Até ao Censo de 1950 no Brasil, saber ler e escrever esteve associado à capacidade de ler e escrever um bilhete simples (SOARES, 2009). Contudo, as expectativas atuais relacionadas ao letramento, de maneira mais ampla, envolvem habilidades que vão além do simples ler e escrever, envolvendo a capacidade de utilização da linguagem oral e escrita demonstrando compreensão do mundo, possibilitando a participação na comunicação, na resolução de problemas e tomada de decisão (Boscolo e Hidi, 2006). Ou seja, no contexto atual não basta apenas o indivíduo saber codificar e decodificar o código alfabético (alfabetizado), mas também saber fazer uso social dessa competência (ser letrado). Soares (2009) enfatiza que o conceito de letramento surgiu da necessidade de cobrir o que o conceito de alfabetização não podia mais englobar na sua definição. À medida que o analfabetismo vai sendo superado, que um número cada vez maior de pessoas aprende a ler 
e a escrever, a sociedade vai se tornando cada vez mais centrada na escrita (cada vez mais grafo cêntrica), um novo fenômeno se evidencia: não basta apenas aprender a ler e a escrever (Soares, 2009). O termo letramento surge então para descrever a condição desse indivíduo que faz uso da leitura e escrita para resolver as exigências da sociedade, cultivando e envolvendo-se em práticas sociais de leitura e escrita. São essas características do letramento que precisam ser desenvolvidas desde os anos iniciais, desenvolvendo nas crianças uma pratica de leitura e escrita crítica e criativa.

Segundo a UNESCO (2005), o letramento é um conceito multidimensional que desafia a elaboração de definições formais e precisas, e considera como importante os processos de leitura e escrita que possibilitem a reflexão crítica sobre textos e contextos, numa dimensão individual e social.

No entanto, faz-se, essencial que a escola crie condições para que os alunos desenvolvam os hábitos de leitura e de escrita, promovendo atividades que possibilitem o desenvolvimento dos processos de letramento tanto no contexto individual quanto coletivo. Sendo a escola um dos principais locais de acesso à cultura escrita, esta deve propiciar aos alunos espaços para se apropriarem dessa cultura e aprenderem a utilizá-la em outros momentos de sua vida, transformando e ampliando sua própria cultura constantemente (Sozim, et al., 2008).

Nesse sentido, o estudo aqui apresentado visa conciliar leitura e escrita de modo a possibilitar uma ressignificação do texto por parte do aluno, através das relações que este poderá fazer com suas experiências pessoais, no processo de criação de narrativas. Segundo Hanke (2003, p.118) as narrativas são um produto arcaico da cultura humana servindo, dentre outras funções, "para acumulação, armazenamento e transmissão de conhecimentos". Estando presente no dia a dia configurando-se como uma atividade linguística de comunicação.

Enquanto gênero literário, a narrativa é o relato de um enredo, que pode ser baseado em fatos reais ou ficcionais1. Já Lebov e Waletzky (1997) consideram narrativa como uma técnica verbal de recapitulação de experiência, em particular uma técnica de construção de unidades da narrativa que correspondem a uma sequência temporal dessa experiência.

Diferentes estudos têm mostrado a potencialidade do uso das narrativas na promoção de letramento. Miller e Pennycuff (2008), por exemplo, apresentam um estudo sobre como a construção de narrativas pode ser empregada como estratégia pedagógica em sala de aula como forma de apoiar a leitura e escrita. Os autores ressaltam que este tipo de estratégia pode promover melhorias na linguagem oral, na compreensão de leitura e na produção textual. Com relação à construção de narrativas utilizando as tecnologias, Silvester et al. (2009) mostraram como esta estratégia pedagógica pode auxiliar estudantes com dificuldade de aprendizagem relacionada à escrita. Garcia \& Rossiter (2010) apresentam uma discussão mais abrangente, mostrando como as narrativas digitais podem ser exploradas como estratégia pedagógica, apoiando-se na força da utilização de histórias pessoais nos processos de aprendizagem. No que diz respeito à utilização da tecnologia na construção destas histórias, os autores alertam, no entanto, que as narrativas não devem ser ofuscadas pelo brilho da tecnologia. Já Snyder (2010) discute as relações entre hipertexto, letramento e mudanças na educação, relatando experiências que ilustram alguns dos desafios enfrentados pela pesquisa em Tecnologias de Informação e Comunicação (TIC) na educação em romper com práticas pedagógicas conservadoras no que diz respeito à

\footnotetext{
${ }^{1}$ Fonte: http://www.revistaliteraria.com.br/generos.htm acesso em julho/2013.
} 
aprendizagem de leitura e escrita.

Tais pesquisas discutem a utilização dos recursos digitais na construção das narrativas de forma genérica, sem propor ferramentas com funcionalidades específicas para apoio ao letramento. Neste trabalho, apresentamos uma proposta de utilização de uma ferramenta de mineração de texto como apoio à construção das narrativas, buscando por meio deste método promover o letramento.

\section{O uso da ferramenta de mineração textual no apoio à construção de narrativas}

A ferramenta de mineração textual Sobek, baseada no algoritmo proposto por Schenker (2003), é capaz de identificar conceitos relevantes em um texto a partir da análise da frequência dos termos nesse material. A ferramenta foi desenvolvida inicialmente para apoiar o trabalho docente tendo sido usada para o acompanhamento da escrita colaborativa em disciplinas na modalidade à distância (Macedo et al, 2009), e para auxiliar o professor na avaliação qualitativa das contribuições dos estudantes em fóruns de discussão(Azevedo et al, 2010). Contudo, mais pesquisas têm sido desenvolvidas com essa ferramenta não auxiliando apenas as tarefas do professor, mas também auxiliando ao aluno.

No que se refere ao apoio em atividades de alunos Klamann et al, 2012 aplicaram a ferramenta para apoiar os alunos na tarefa de sumarização de textos; no auxilio ao processo de produção textual (Klamann et al, 2009). E no apoio a produção de narrativas fitction (Campelo, 2013). Em sua versão recente, foi acrescentada à ferramenta a opção de visualizar os conceitos relevantes do tex to em um grafo de imagens, o que originou a ideia de se aplicar essa ferramenta com alunos dos anos iniciais do ensino fundamental para apoiar no desenvolvimento de letramento através de construção de narrativas.

A versão da ferramenta que gera um grafo de imagens foi desenvolvida a partir de uma API de busca do Google ${ }^{2}$, que permite com que a busca seja feita em tempo real. A figura 2 mostra o grafo extraído de um texto sobre poluição da água ${ }^{3}$.

\footnotetext{
${ }^{2}$ API disponível em https://developers.google.com/custom-search/v1/overview. Acesso em julho/2012

3 Texto disponível em: http://pt.wikipedia.org/wiki/Polui\%C3\%A7\%C3\%A3o_da_\%C3\%A1gua, acessado em setembro de 2013
} 


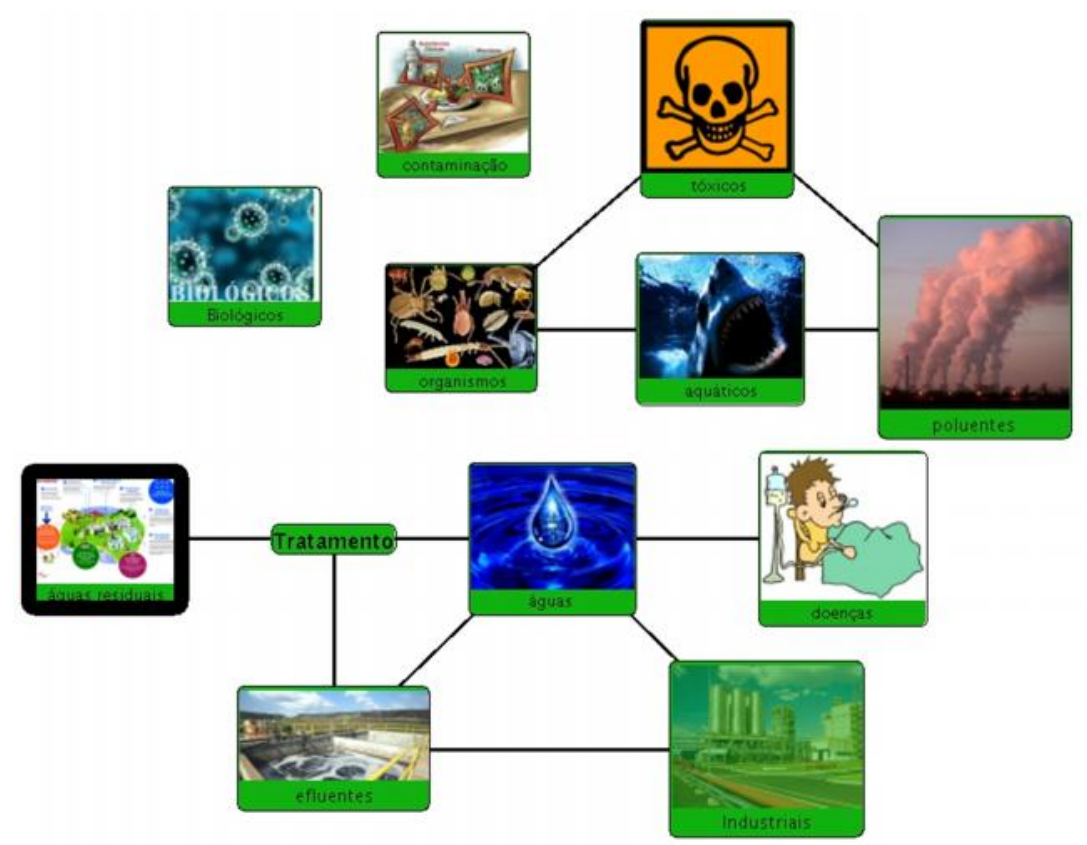

Figura 1: Grafo de conceitos correspondentes a um texto sobre poluição da água.

A pesquisa aqui apresentada propõe o emprego da ferramenta de mineração de texto para apoio à criação de narrativas. Segundo Hall e Strangman (2002), a visualização gráfica de relações entre fatos, termos e ou ideias, pode trazer determinados benefícios aos alunos, tais como:

- Ajudá-los a organizar suas idéias;

- Auxiliá-los a conectar conhecimentos prévios a novos conceitos;

- Fornecer representações que os auxiliem pensar, escrever, discutir, analisar, planejar e relatar;

- Ajudá-los a manter o foco em pensamentos e idéias, levando à compreensão e interpretação.

Com isso, a ferramenta abre possibilidades para que um mesmo texto possa ser representado também de forma gráfica. A ferramenta proposta é usada aqui como disparador de ideias que ajuda o aluno a escrever sua narrativa focada em um assunto especifico. A proposta foca não apenas na representação gráfica originada pela ferramenta, mas também na reflexão sobre o texto disponibilizado aos alunos, levando a releituras que dão novos significados e melhoram a compreensão do material lido.

Sendo assim, a proposta de intervenção pedagógica para elaboração de narrativas é composta pelos seguintes passos:

a) Leitura de texto de referência: propõe-se como passo inicial da construção de narrativas a leitura de um texto de referência que possibilite explorar diferentes temas e relacioná-los às vivências dos próprios estudantes, explorando a ideia levantada em Miller \& Pennycuff (2008) sobre a construção de narrativas como forma de trabalhar áreas diversas.

b) Extração de grafo a partir do texto: o passo seguinte diz respeito à extração do grafo contendo os principais termos do texto empregando a ferramenta Sobek.

c) Análise do grafo: após a extração automática do grafo, solicita-se aos alunos 
que procurem analisá-lo com vistas a identificar os quão apropriados são os termos apresentados na forma de imagens. Este passo, muitas vezes leva os estudantes a reler o texto, possibilitando também uma maior reflexão sobre o material lido.

d) Edição do grafo: neste momento, os estudantes podem editar o grafo removendo nodos que acreditem ser irrelevantes para a construção de uma história relacionada ao tema, e também acrescentando nodos, se assim acharem necessário.

e) Construção da narrativa: apenas neste momento os alunos começam efetivamente a elaborar suas histórias a partir dos grafos editados. A elaboração das histórias pode contemplar tanto sua escrita, quanto a utilização de desenhos, imagens extraídas nos grafos, ou outros materiais que auxiliem os aprendizes na construção de suas histórias. $\mathrm{O}$ fato de a ferramenta apresentar imagens de conceitos relevantes sobre um determinado texto possibilita a construção das narrativas centrada em um assunto específico.

Nessa perspectiva, a ferramenta é empregada como um disparador de ideias que pode auxiliar o aluno a delimitar sua escrita focando em um assunto específico.

\section{Estudo sobre aplicação da ferramenta de mineração Sobek}

Para validação da pesquisa, foi realizado um estudo de cunho qualitativo envolvendo alunos do ensino fundamental, que participaram de uma oficina em um laboratório de informática organizado em parceria com o projeto de Letramento e Matemática (LEMA) da Universidade Estadual do Paraná, Campo Mourão.

Foi realizada com os estudantes uma atividade de construção de narrativas empregando a ferramenta de mineração textual Sobek e a metodologia propostas. Foram utilizados protocolos de observação participativa e questionários como instrumentos de coleta de dados. Os alunos seguiram os passos de a a e descritos na seção anterior para construir suas narrativas. Inicialmente, os alunos fizeram a leitura de um texto sobre meios de comunicação, e este foi em seguida minerado pela ferramenta para geração dos grafos que serviriam de "elemento disparador" para construção das narrativas.

Cabe ressaltar que não se buscou avaliar neste estudo a ortografia das produções textuais, mas procurou-se analisar em que medida o grafo de conceitos/imagens apresentado pela ferramenta contribuiu no desenvolvimento de narrativas relacionando um tema especifico com as experiências dos estudantes.

O estudo foi realizado com 26 alunos de uma escola de ensino fundamental em Campo Mourão, através de oficinas desenvolvidas num laboratório de informática na Universidade Estatual de Paraná - Campus de Campo Mourão. Os alunos foram separados em dois grupos, de $5^{\circ}$ e $6^{\circ}$ ano respectivamente. A atividade consistia em "construir uma narrativa ou história relacionada ao tema proposto no texto de referencia, com experiências reais ou ficcionais". Inicialmente fez-se a leitura do texto individualmente e em conjunto e discutiu-se sobre o assunto abordado. Em seguida, empregou-se a ferramenta Sobek para extrair do texto os conceitos mais relevantes e representá-los de forma gráfica. Com base nesta representação, os alunos partiram para a edição dos grafos e subsequente escrita de suas narrativas.

A figura 3 apresenta o grafo extraído do texto "Os meios de comunicação", 
utilizado como referência no estudo realizado.

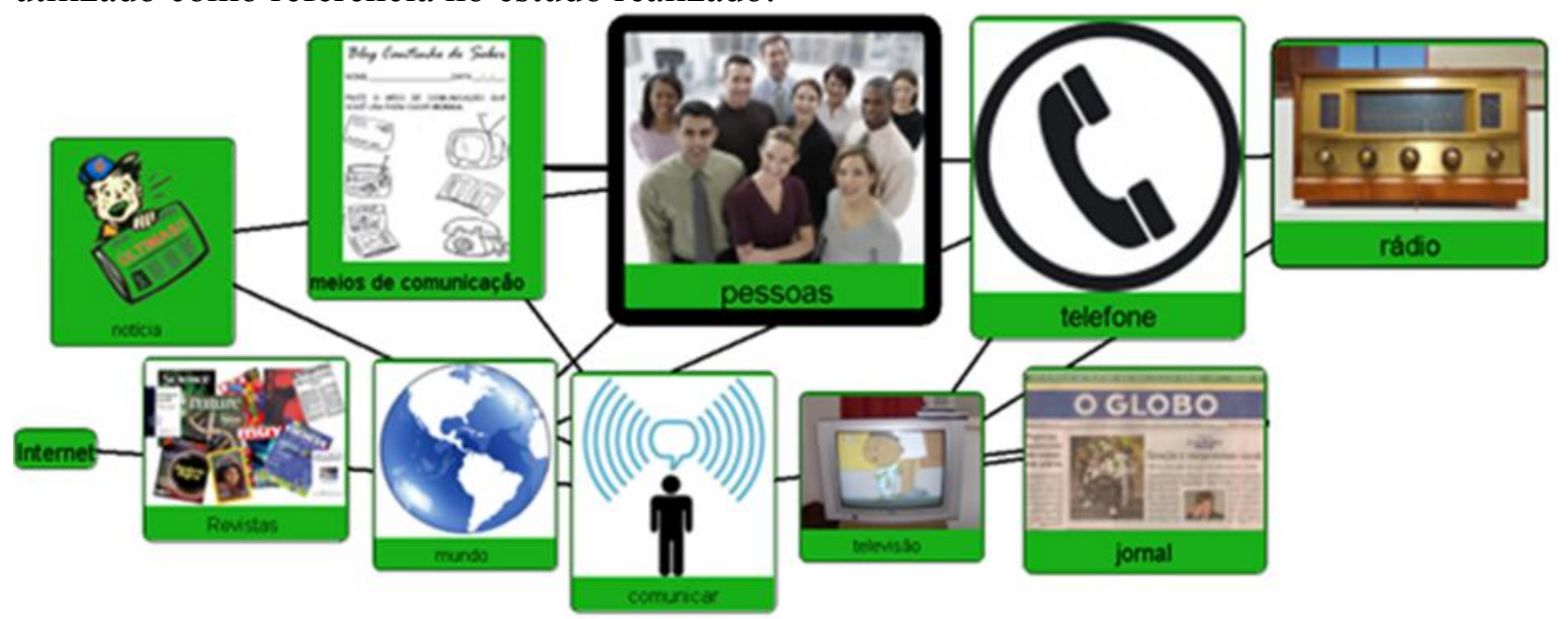

Figura 2: Grafo usado como referência para os alunos escreverem suas narrativas.

Enquanto escreviam suas narrativas, o texto de referência e o grafo editado foram quase sempre mantidos abertos pelos alunos durante a realização da atividade. Tal fato mostra o empenho dos estudantes em ser fiéis à temática do texto.

Das narrativas produzidas, percebeu-se que os alunos não só se preocuparam em utilizar nas suas histórias os termos apresentados pela ferramenta, mas também buscaram apresentá-los de forma contextualizada, relacionando-os com fatos importantes em suas trajetórias. Neste sentido, entende-se que quando a escrita é tomada como elemento central no desenvolvimento do letramento, é importante que traga interferências do contexto de vida do indivíduo.

No estudo realizado, tomou-se a concepção de narrativa defendida por Hanke (2003), na qual “a exigência mínima para se caracterizar uma narrativa é uma ligação temporal entre pelo menos duas sentenças". Essa concepção torna-se relevante em fases do letramento nas quais os alunos ainda não conseguem trabalhar com estruturas narrativas mais complexas (Almeida e Freitag, 2001).

Inicialmente, as narrativas dos estudantes foram analisadas buscando-se identificar evidências de que a ferramenta auxiliou-os na organização de ideias. Também buscou-se verificar se o emprego dos grafos ajudou os alunos a delimitar a temática de suas narrativas, e iniciou processos reflexivos que resultaram em conexões com conhecimentos prévios.

Abaixo é apresentado o quadro 1 com um exemplo de narrativa construída a partir do grafo gerado pela ferramenta e editado pelo sujeito A.

Quadro 1: Narrativa construída pelo Sujeito-A

\section{Sujeito-A: $5^{\circ}$ ano - Os meios de comunicação}

Era uma vez, dois tipos de meio de comunicação o celular e o telefone, mas eles brigavam tanto que um dia o celular disse para o telefone:

As pessoas gostam mais de mim do que você por que eu tenho internet e não tenho fio, eu tenho som tem como eu escrever textos porque tenho começo meio e fim e tenho a força que me permite as pessoas ouvir rádio e ver jornal e também a me comunicar com as outras pessoas, por exemplo, ler revistas pela internet. 
A breve estrutura narrativa apresentada pelo sujeito-A mostra sua compreensão sobre alguns meios de comunicação que constavam no grafo extraído pela ferramenta, e que provavelmente se fazem mais presentes em sua vida. Sua história evidencia características de cada um, usando o celular e o telefone (fixo) como personagens da narrativa.

No quadro 2, apresentando a narrativa construída pelo sujeito-B, percebe-se o uso dos meios de comunicação não como personagens, mas levando em conta sua função de possibilitar a interação entre as pessoas, relacionando o fato a uma história com fatos marcantes.

Quadro 2: Narrativa construída pelo Sujeito-B da pesquisa

\section{Sujeito-B: $5^{\circ}$ ano - A vida terrível de uma garota}

Era uma vez uma menina, que muito pequena, não conheceu sua mãe. Logo quando ela nasceu foi levada para um orfanato. A menina cresceu e lá a raiva e o ódio tomava conta do coração dela. Cada dia que passava, ela sentia mais raiva da pessoa que colocou ela naquele lugar. Ela completou 18 anos de idade e saiu daquele lugar ela foi procurar a mãe dela. Primeiro ela procurou nos jornais depois na internet ela achou uma mulher com as mesmas características dela e que também perdeu sua filha, ela começou ase comunicarse com a mulher.

Um belo dia ela estava olhando uma revista era de um homem que tirava crianças da mãe e colocava elas num orfanato, e lembrou daquele rosto. Com todas as acusações os policiais o matarão. E a menina com sua Mãe viverão felizes para sempre.

Percebe-se também como esse aluno(a) utilizou enredos frequentes em novelas e filmes, trazendo evidenciadas as funções que os meios de comunicação exercem nesse contexto como forma de focar no tema central apresentado através do grafo extraído do texto.

Fica evidente nestes dois exemplos o esforço dos alunos em criar histórias que envolvessem suas experiências, relacionando-as com os temas centrais do texto de referência, de acordo com proposta apresentada na seção 3.1. Mas cabe destacar aqui que o mesmo pôde ser observado na maior parte das narrativas produzidas pelo grupo de 26 alunos.

Em um segundo momento, disponibilizou-se aos estudantes questionários para que pudessem registrar suas percepções quanto ao emprego da ferramenta de mineração textual para apoio à construção das narrativas. As respostas dos questionários disponibilizados aos estudantes foram resumidas na tabela 1 .

Tabela 1: Resultados do questionário

\begin{tabular}{l} 
Qual o papel da ferramenta de \\
mineração textual em cada atividade \\
abaixo: \\
Ajudou a encontrar ideias importantes \\
no texto? \\
Ajudou a organizar as ideias antes de \\
iniciar a escrita? \\
\hline Ajudou a compreender melhor o texto? \\
\hline Motivou a escrita da historia/narrativa? \\
\hline Ajudou na escrita da historia/narrativa? \\
\hline
\end{tabular}

\begin{tabular}{l|l|l|l|l}
$\begin{array}{l}\text { Muito } \\
\text { importante }\end{array}$ & Importante & $\begin{array}{l}\text { Nem muito } \\
\text { nem pouco } \\
\text { importante }\end{array}$ & $\begin{array}{l}\text { Pouco } \\
\text { importante }\end{array}$ & $\begin{array}{l}\text { Nem um } \\
\text { pouco } \\
\text { importante }\end{array}$ \\
\hline $19=73 \%$ & $7=27 \%$ & $0=0 \%$ & $0=0 \%$ & $0=0 \%$ \\
\hline $11=42 \%$ & $13=50 \%$ & $2=8 \%$ & $0=0 \%$ & $0=0 \%$ \\
\hline $15=58 \%$ & $8=30 \%$ & $3=12 \%$ & $0=0 \%$ & $0=0 \%$ \\
\hline $16=62 \%$ & $5=19 \%$ & $2=8 \%$ & $3=11 \%$ & $0=0 \%$ \\
\hline $9=35 \%$ & $16=62 \%$ & $0=0 \%$ & $0=0 \%$ & $1=3 \%$
\end{tabular}


Com base nas respostas do questionário percebe-se que a maioria dos sujeitos da pesquisa considerou que o uso da ferramenta de mineração textual ajudou no processo de compreensão textual e na atividade de escrita. Destacam-se também os seguintes resultados:

- Todos os alunos consideraram que a ferramenta foi muito importante $(73 \%)$ ou importante (27\%) na identificação das ideias centrais do texto;

- $92 \%$ dos alunos consideraram que a ferramenta foi ou muito importante $(42 \%)$ ou importante (50\%) na organização das ideias antes de iniciar a escrita;

- $88 \%$ dos alunos consideraram a ferramenta como tendo sido muito importante $(58 \%)$ ou importante (30\%) na compreensão do texto;

- $81 \%$ dos alunos consideraram a ferramenta foi muito importante $(62 \%)$ ou importante (19) para motivar o processo de escrita;

- $97 \%$ dos alunos consideraram que a ferramenta foi muito importante $(35 \%)$ ou importante $(62 \%)$ no apoio à escrita das narrativas. Apenas $3 \%$ desses alunos julgaram a ferramenta como desnecessária no processo da escrita.

O resultado dos questionários mostra que, de acordo com a percepção dos estudantes, a ferramenta auxiliou-os a identificar as ideias centrais do texto, a organizar essas ideias antes de iniciar sua escrita, a compreender ideias centrais do texto, além de ter um papel motivacional na realização da tarefa de escrita.

Apesar de 3\% dos alunos ter julgado que a ferramenta não ajudou em nada no processo da escrita, os demais estudantes consideraram a ferramenta como sendo importante, o que mostra o potencial desta para a sua aplicação em contextos de desenvolvimento de leitura e escrita como forma de promoção de letramento.

\section{Conclusão}

A construção de narrativas é um exercício de construção da linguagem em todas as formas. Nesse artigo procurou-se empregar esta característica das narrativas para, através do uso de uma ferramenta de mineração textual, instigar alunos no seu processo de escrita.

$\mathrm{O}$ estudo realizado mostrou como a ferramenta e metodologia propostas podem instigar os alunos em atividades de produção textual, ajudando-os a escrever histórias orientadas a um tema específico.

Por sua forma de operação, a ferramenta permite que a construção de narrativas relacionadas a um determinado tema seja feita de forma reflexiva, desenvolvendo habilidades de interpretação e relacionamento de ideias. Contudo, ao invés de centrar-se estritamente no tema proposto, o método permite dar mais significado à escrita dos estudantes ao conduzi-los na criação de histórias que resgatem suas próprias experiências, sejam estas reais ou ficcionais.

$\mathrm{O}$ estudo permitiu concluir que a ferramenta pode ser uma alternativa tecnológica com potencial para enriquecer a construção de narrativas, devido a sua natureza que possibilita a extração de conceitos relevantes de um texto apresentando-os em forma de grafo de imagens/conceitos. Tal característica permite ao professor trabalhar com determinado tema, ao mesmo tempo em que propõe uma atividade de apoio ao letramento.

\section{Referências}


ALMEIDA, Ayane N. S., FREITAG, Raquel M. Caracterização de Narrativas Orais e Escritas e sua Interferência no Processo de Letramento em Séries Iniciais. In: VI Simpósio Internacional de Estudo de Gêneros Textuais. Agosto/ 2011.

AZEVEDO, Breno F. T; REATEGUI, Eliseo B; BEHAR, Patricia A. Qualitative Analysis of Discussion Forums. In: IADIS International Conference on e-Learning. Freiburg, Germany 2010.

GARCIA, P. ROSSITER, M. Digital Storytelling as Narrative Pedagogy. In: D. Gibson e B. Dodge (Eds.), Proceedings of Society for Information Technology \& Teacher Education International Conference, Chesapeake, VA: AACE, 2010, p. 1091-1097. HALL, Tracey; STRANGMAN Nicole. Graphic Organizers. In: National Center on Accessing the General Curriculum, 2002. Disponível: http://aim.cast.org/sites/aim.cast.org/files/NCACgo.pdf. Acesso em 07/10/12.

HANKE, Michael. Narrativas orais: formas e funções. In: Contracampo, v. 9, 2003.

HIDI, S. \& BOSCOLO, P. Motivation and Writing. In: MACARTHUR, C. A., GRAHAM, S. e FITZGERALD, J. (Eds). Handbook of Writing Research. New York, NY: The Guildford Press, 2006, p. 144- 157.

LABOV, William. WALETZKY, Joshua. Narrative analysis: Oral versions of personal experience. Journal of Narrative \& Life History, V.7(1-4), 1997.

MACEDO, A. REATEGUI, E, LORENZATTI, A. BEHAR, P. Using Text-Mining to Support the Evaluation of Texts Produced Collaboratively. In: Education and Technology for a Better World: Selected papers of the 9th World Conference on Computers in Education, Bento Gonçalves, Brazil. Springer, 2009.

MACEDO, Alexandra L et al; Acompanhamento da Interação e Produção Textual Coletiva Através de Mineração de Textos. Informática na Educação: teoria \& prática; Porto Alegre, v.14, n. ${ }^{\circ}$, Jul./Dez. 2011.

MACHADO, Irene A. Narrativa e Combinatória dos Gêneros Prosaicos: A Textualização Dialógica. Itinerários - Revista de Literatura; n.12. Araquara, 1998. p. 33-46

MILLER, S. \& PENNYCUFF, L. The Power of Story: using Storytelling to Improve Literacy Learning. Journal of Cross-Disciplinary Perspectives in Education. v. 1, n. 1, 2008, p.36-43.

SCHENKER, Adam. Graph-theoretic techniques for web content mining. Graduate School Theses and Dissertations. 2003.

SNYDER, I. Antes, Agora, Adiante: hipertexto, letramento e mudança. Educação em Revista. Belo Horizonte v. 26, n. 3, 2010.

SOARES, Magda. (2009). Letramento: Um Tema em três Gêneros. Belo Horizonte: Autêntica, $3^{\mathrm{a}}$ ed.

SOZIM, M. M, et al. Alfabetização e letramento - uma possibilidade de intervenção. In: Revista Conexão UEPG; v. 4, n.1, 2008, p 44-48.

SYLVESTER, R, GREENIDGE, W. Digital Storytelling: Extending the Potential for Struggling Writers. In: The Reading Teacher, n. 63, v. 4, 2009. p. 284-295.

UNESCO. Aspect of Literacy Assessment: Topics and Issues from the UNESCO Expert Meeting. Paris. 2005 